An article instead of PREFACE

\title{
EDUCATION IN THE POST-SCIENTIFIC CULTURE
}

\author{
ALEKSANDER KOBYLAREK \\ Institute of Pedagogy, University of Wrocław \\ ul. J. Wł. Dawida 1, 50-527 Wrocław, Poland \\ E-mail address: aleksander.kobylarek@gmail.com
}

\begin{abstract}
This essay presents an interdisciplinary study of the role of the net society in education, and the appearance of a post-scientific culture in the Internet. However, the theory of a society rendered stupid by the Internet is one-sided and does not bear closer analysis. The appearance of incompetence and stupidity is only one of many behavioural traits of people using the Internet, and the net society, despite its specific nature, is in many ways similar to those functioning outside the Internet. Post-scientific culture need not be the only (or even the dominant) voice in the general Internet discussion. The creation of net societies which can perform the role of groups relating to a new scientific culture in the Internet have particular significance. A significant role can be played by new leaders and educated individuals who should be engaged in promoting a scientific culture. The Internet creates suitable conditions for transformative and emancipative learning, and it is only necessary to perceive them and use them appropriately.

Key words: Internet, transformative learning, emancipative learning, fourth wave, pre-figurative culture
\end{abstract}

We currently live in a world in which we have to tackle a wide range of specific problems. Some of these are completely new, whereas others appear to be very similar to those which we have had to tackle in the recent past. These new problems, which we have not previously encountered, are above all connected with the development of new technologies, particularly the Internet. Perhaps the most important among these recurring problems are those which are evident in controversial political activity.

There are also specific problems with which civilization has been struggling for centuries, and for which we are still are unable to find solutions, despite an awareness that their continuation poses a threat to our well-being, as in the case of the destruction of our environment. Paradoxically, although we have been acutely aware of this problem for years, we have so far been unable to convince our decision makers to take effective pro-ecological activities to halt these adverse changes. (Meadows, Meadows, Randers, Behrens, 1972). 
Changes in individual areas would perhaps not have been so catastrophic if they had not been intensified by the imposition of adverse elements. Technological changes, which were supposed to increase comfort and raise the quality of life, could lead to the formation of technologically advanced societies. Meanwhile, we very often use technological advantage to gain supremacy or as a tool for economic or political domination. Until the last century, adverse changes in the environment occurred relatively slowly, but the rapid advance of civilization and the demand for raw materials has accelerated exploitation and the devastation of the environment. To add to this evil, politicians unscrupulously take advantage of available technologies in order to manipulate citizens and then exploit their naivety to ruthlessly carry out their particular interests.

Ultimately, living organisms have become victims of these twists in circumstances. This includes man himself, who is still dependent on the function of other animal and plant species, despite the development of advanced technologies. Disadvantageous political and technological convolutions and environmental changes have created a hostile surrounding for us. Thus, we cut off the branch we are sitting on, and striving for a greater degree of comfort and quality of life may actually lead to their loss, perhaps irreversibly.

Technological change affects all spheres of life, including culture (with science as a part of it) and education, understood here as an appropriate tool for developing wisdom. One can dispute the genesis and origins of the views currently held by thinking people, but there is no doubt that the virtual world is the reality which started the fourth wave of change (Toffler 1991, Kobylarek 2017). And although the Internet was created and disseminated by the academic community, it is often perceived as a source of stupidity and misinformation. This also affects practically every sphere of life, from minor daily news to the world of science, politics and business. It would be a mistake to blame the Internet for all the world's stupidity, but in the virtual world examples of absurd election results, boorishness and intellectual poverty are all too often evident. The world wide web and the virtual communities it has created have become a kind of catalyst, or at least a distorting mirror in which human iniquity and stupidity is reflected.

In observing such boorishness, stupidity and arrogance, it is worth considering the causes. How is it that we have sunk to such an unprecedented level of ignorance, and yet are unable to turn away from it? This interdisciplinary essay is an attempt to discover the causes, but not necessarily solutions, which will have to come through a much greater engagement by society, not just individual academics, artists and thinkers.

The Internet should be treated as a canvas, a structure and base for a whole range of phenomena which are redefining our culture and creating a specific environment for social life, and the more this environment develops, the more cultural and civilizational challenges become apparent. It is difficult to see these challenges as some kind of threat, because change is something natural and all-embracing, and we have to get used to it whether we like it or not. We can only talk of threat if we adopt the point of view of a displaced culture. 
This does not seem to be appropriate, inasmuch as only closer analysis and an understanding of the changes occurring can lead us to an answer to the question of how to survive, or at least how to take advantage of these changes so that our life has some sense.

\section{POST-SCIENTIFIC CULTURE}

The creation and expansion of the Internet is forcing us to change our perception of the creation and function of culture. There is much to indicate that a significant number of the theories and concepts of culture which were formulated up to the $20^{\text {th }}$ century need to be verified. Is there any sense, for example, in speaking of 'popular culture', when everything has already become an element of popular culture? Is there also any sense in speaking about post-modernism, when all that remains is a confusion of hybridized virtual species? Is it worth in the end speaking of a variety of equally justified discussions, when there is a characteristic flight from freedom into one, or at most a handful of value systems and two or three basic aesthetics.

A hundred years ago José Ortega y Gasset (1929) and Stanisław Ignacy Witkiewicz (1919) predicted a phenomenon which could not fully come to pass until the era of the Internet - that is, that the masses would impose their own tastes and criteria for what is worthwhile. Thus, material currently in circulation is above all that which appeals to the masses and not that which might enrich us intellectually and aesthetically. Sometimes content can be found which appeals to 'connoisseurs', but it is not they who define general cultural trends because they have become an ever narrowing group of Lampedusa's 'leopards', a dying species of aesthetes.

Conducive to this is the culture of the image, and the slogan "a picture tells a thousand words" has become a mantra for the net generation. We migrate fairly quickly from those social media based predominately on text, such as Twitter and Facebook, to those based on images, such as Instagram. Besides, the first two mentioned are also undergoing a radical transformation. One only has to look at the dialogue between users in the form of comments to images to see that it is more often a game with emoticons rather than verbal comment. This is not to lay blame at anyone's door or describe some kind of pathology, because these processes should be treated as a change which needs to be understood in order to function effectively.

Perhaps in time we will develop the language of icons so far as to be able to write poems or philosophical tracts with them, even though at the moment such type of communication appears to be superficial and of little value. Its value depends on a particular aesthetic of the virtual form, which is useful in self-presentation, and the content depends on constructing symbolic or ambiguous communications. A mass audience will take fare more notice of the aesthetics of self-presentation than any deeper meaning or symbolic context. 
In a culture dominated by images, communication should be short and relevant. A title and headline and at most a short descriptive paragraph can be read in a short space of time, allowing us to turn to other content which may be more interesting. Looking at, relishing and experiencing iconicity are in opposition to scientific thinking, insofar as virtual reality and mediation communication create a world full of information bubbles and echo chambers.

This new kind of culture, created and shared by internet communities, is beginning to displace other more traditional forms. Of course, the elite has always been a very narrow minority, and always will be, but in education that which is elitist and characterized by a high artistic level, the acquisition of culture and the highest values achieved by man is just as important as commonplace popular culture. On the other hand, there is no doubt that the culture of the fourth wave is dominating and flooding all other cultures.

Popular culture has undergone a fundamental transformation and does not reflect the most important features of the net society. It appears to be an 'in action' culture, created and disseminated by ordinary users of the Internet, recreating their own identities, sometimes opposing or ignoring their identity in the real world (Levinson, 1997). Culture transmitted by experts and cultural centres, strengthened by critical comment, fades into the background. That which is alive and pulsing in the net comes from the net itself. Virtual communities have no central point or unquestionable authorities, therefore their values are created and cultivated locally, wherever a group of adherents to such values comes together. For such communities, their authority figures are virtual cultural leaders, who have mastered perfectly the technology and aesthetics of self-presentation in the net. Authority figures and values originating from outside the net may be added to this cultural bloodstream.

Such a method of creating and disseminating icons and memes leads to totally new phenomena, semantic contexts and games which are understandable only to those in a given virtual community. At the same time, cultural players from outside this world suffer from exclusion because often they are not even able to understand the messages contained in these virtual discussions. For that matter, here the games metaphor is probably most relevant, as internet users as players live on the periphery of a common reality, playing games known only to themselves and based on unwritten rules.

Science is not really the centre of interest for players in virtual communities, unless perhaps when it comes to the transfer of information, when a scientific explanation is needed to clarify certain matters. However, we generally use the Internet for communicating with others. It is also a means of building our own position among our group of friends and also of maintaining contact.

The barely perceptible presence of academics in these virtual communities means that it is easy to publish and disseminate false information which, once in circulation, takes on its own life and causes much misunderstanding. A lack of moderation or verification in some virtual communities facilitates publication, while a lack of vigilance by moderators facilitates dissemination. False information and fake news become particularly dangerous when they are reposted by 
reputable information websites or scientific authorities not well versed in the use of modern technologies. So-called 'scjentobryci' (Błaszczyński, 2014), wishing to follow the fashion for technology and reach out to the younger generation by copying their mode of expression, lose all authority just as if they had not used the technology at all - this applies even to university professors.

\section{SOCIETY BEYOND TIME AND SPACE}

A withdrawn scientific elite, confused 'scjentobryci' and the ill-informed virtual masses eventually become the catalyst for a negative perception of the scientific possibilities of the Internet generally, and particularly among ordinary users. This situation is further complicated by the privatization of scientific achievement on the form of paid on-line services publishing and making available the results of scientific research for a fee. In this way the Internet, which appeared to make it possible for society to become more free, egalitarian and fraternal, has in effect begun to duplicate the world which it created - a world full of inequality and forbidden places, with various cultural and scientific propositions depending on intimacy and know-how. In such a world there still exist micro-worlds of academic specialists, those who have knowledge and are in the know, which can be compared to the intra-mural activities of expert academic communities within universities. Side by side we have a meeting place composed of Internet micro-worlds, open to all, and inhabited by ignorant, misled and manipulated people, which in turn can be compared to the extra-mural academic world. Thus, it would appear that by definition this meeting place is doomed to manipulation, incitement, deceit and digression. Virtual micro-worlds also appear to be doomed emotional manipulation, racism and coarse comments as well as the unpleasantness of conversing with people who are intellectually or spiritually lacking.

We should not be surprised, therefore, that many academics perceive the Internet as a threat to traditional cultural values which have been developed by advanced societies. The high temperature of discussion and commentary lead us to doubt whether a bickering society is capable of using its intellect in an appropriate manner.

Virtual cultures located in the universally accessible information highway not infrequently are reminiscent of the world of wild neo-tribes (Maffesoli, 1996). They are alien in form and content, created by the human world, but incongruous to it and deformed. These cultures employ their own netiquette and specific language and also create their own rules of behaviour. Thus, the independence of the virtual world from the real world can also be a problem for the hierarchical world of science. Academics themselves feel insecure in a world of critics and mockers, especially as their authority is often equal to anybody else's. It therefore seems that the primary values of the virtual world, such as freedom and the joy of playing games, must be paid for by the loss of independence of intellect. 
The image of the Internet as a threat is propagated above all by those who could or could not recognize the possibilities of technology. Insightfully, studying has not turned out to be so distant from the reality of those who created it. Above all, various communities exist in both worlds. Those communities which are open, easy to enter, make comments and take part in discussions are somewhat reminiscent of 'railway station' community, a diverse crowd for whom the one common characteristic is cyberspace. Just as in the real world, alongside these communities there are communities of specialists, closed and elitist, and often invisible to the outside world. Such communities are well-versed in the possibilities of technology, supplementation of knowledge, professionalization and the strengthening of communication. They can exist beyond time and space, but also often respond to the needs of their members and are more suitable to overcome time and space by, for example enabling communication in real time, determining and amending priorities, establishing contacts and obtaining feedback.

Digital exclusion is not the result of poverty, nor does wealth guarantee inclusion in the virtual world. Understanding the available technology and making use of it depends more on the engagement of the those who are themselves interested. Those who are less interested or sceptical will fall into digital exclusion and depreciate their social position in the real world, because both worlds complement and co-operate with each other. Those who are able to use the new technologies to the full have the opportunity to become new leaders and authority figures, somebody more than simply instagrammers or influencers. The real world has already been 'modified' by virtual reality through, for example, fake news and political propaganda disseminated by armies of trolls and bots. We have an opportunity to reverse this trend if new authorities emerge in the virtual world, who combine wisdom with technological ability, and if we can return reason to the anarchized virtual world. Currently there are not many of such authorities, and most of them exist in closed societies which are not particularly interested in building an intelligent community. They may also be discouraged by the superficiality of open internet discussion, a lack of suitable respondents or an atmosphere of frivolity and disregard. It is worth making those with potential aware that media influence should go hand in hand with responsibility and a sense of mission. In contrast, without the participation of knowledgeable experts virtual communities will become more chaotic and anarchic, manipulated and ruled by emotion.

\section{EMANCIPATORY AND TRANSFORMATIVE EDUCATION}

Deciphering cause and effect symbols, contexts and relationships requires good preparation, in other words a suitable education. The complicated virtual world needs experts who are translators rather than legislators as in the real world.

Not the least important are the users of the virtual world themselves. They will decide whether to participate in a manipulated Internet, become members 
of an elite knowledge society, or remain digitally excluded. Preparation for life in the virtual world can only be partly the result of formal education. A certain intellectual maturity and technical ability are essential for full and satisfactory participation in the Internet community. Common sense, circumspection, good manners, curiosity, precision, self-restraint or active engagement are all key competences in Internet discussions, and just as important as a familiarity with netiquette and the language of emoticons.

Formal media education can help in understanding the basics of the virtual world, but it cannot replace practical experience, intuition, self-development and the effort needed to cope with an electronic text.

In this situation it depends on Internet users themselves to what degree they will be able to take advantage of the benefits of technology. The greater the experience, intuition and reflectiveness, the greater the satisfaction in participating in the virtual world. Just as in the real world, engagement in education and self-development will be the key to success in understanding the virtual society and effective activity in the Internet.

Thus, emancipatory and transformative education take on a special significance, and thanks to this we gain a new perspective in our perception of reality Mezirow, 1991). This type of learning requires more effort, greater interest in the world about us and its objects and ideas, and above all reflection. Taking these observations into account, it is necessary to express a fear as to how far people are capable of achieving emancipatory and transformative education. Doubts as man's ability to free himself from cognitive limitations and leave the simulated world (Baudrillard, 1988) is sufficient to convince us of the limited competences of the average person. Some hope is engendered by the fact that the fast changing world of new technologies will require a greater necessity to redefine reality, and together with this an intellectual effort in understanding the character of change and its place in the world.

Opponents of the new media claim that the opposite is true. The more we make life comfortable, the more it will free us from intellectual effort. In effect, thinking and solving problems will be taken over by artificial intelligence.

It seems that we are at the beginning of a long road. Somewhere on the horizon we see the world of the fourth wave, full of new technologies and interconnected virtual worlds which are taking over and displacing the real world. The technological possibilities we possess enable us to create a better world, but our intellectual competences throw doubt on our ability to take advantage of these technologies. Thus, we return to the basics of education. The technological race of the fourth wave will be won by communities of knowledgeable citizens who will be able to make correct decisions and shape their lives rationally. The other world will consist of people who are manipulated, emotional, submerged in simulation, suspicious and ignorant, functioning so to speak as political cyborgs as long as democracy survives.

Brutal on-line discussion and absurd election results leading to nonsensical political decisions convince us that we are on the edge of an abyss and closer to self-destruction than we have ever been. Knowledgeable and thinking 
people look with sadness on the picture of stupidity, unconcern, ignorance and thoughtlessness which we see in the electronic media. Academics are becoming side-lined when expertise and scientific recommendations are essential in a world of pure political power which is guided only by its own whims in making decisions. In my opinion, the scientific world is becoming submerged in depression.

Education has always been perceived as the best tool for change in the world. However, it seems that among part of modern society it has suffered defeat. Even if we establish that education can be the proper way to change mentality, it would require many decades to build awareness and equip ourselves in the key competences necessary for emancipatory education. On the one hand we don't have time for this, and on the other hand we cannot duplicate present forms which have clearly proved ineffective. We could try copying the best solution, but rather in the form of an experiment, because education is closely connected with the culture of society and cannot be transplanted to other soil without side effects.

It appears that most probably there will be a soft technological revolution which will expand the net. There is already a growing generation submerged in the virtual world for whom the Internet is the fundamental place in which they exist. From this generation there will certainly be found leaders, currently lacking, who will be able to combine familiarity with technology with charisma and a mission. From this also arises the justifiable presumption that transformative education, just as a large part of socialization, will be transferred to the net. It appears that we are now witness to the beginning of this process.

The next important change in the sphere of emancipatory education will be the dominance of the pre-figurative culture (Mead, 1970), in which suitably aware internet users will learn from each other by taking advantage of existing sources of information as well as developing their own key competences by participating in virtual communities, which can to some extent be compared to the elite education environments functioning before the advent of the Internet.

Education may provide a new chance to construct an intelligent society based on knowledge, if only we can take advantage of the potential of net technology. Where for many lurk stupidity and incompetence, it is worth noticing strength wisdom, and knowledge. Whether the virtual world will have an educational potential, or whether it becomes a rubbish dump, an emanation of pure stupidity and a place for fraud and manipulation, depends on the function of interpreters and moderators, as well the educational needs of ordinary people. 


\section{REFERENCES}

[1] Baudrillard, J. (1988). Selected Writings. Stanford: Stanford UniversityPress.

[2] Błaszczyński, K. (2014). Konsekwencje globalistycznego modelu nauk. Ogrody Nauk i Sztuk, 4, pp. 13-22.

[3] Kobylarek, A. (2017). Polish Humboldtian University in the Face of Paradigmatic Change. Cambridge Scholars Publishing.

[4] Levinson, P. (1997). The Soft Edge: A Natural History and Future of the Information Revolution. New York: Routledge.

[5] Maffesoli, M. (1996). The Time of the Tribes: The Decline of Individualism in Mass Society (Published in association with Theory, Culture \& Society). Thousand Oaks: Sage Publications Ltd.

[6] Mead, M. (1970). Culture and Commitment. New York: Garden City.

[7] Meadows, D. H., Meadows, D. L., Randers, J., \& Behrens III, W. W. (1972). The Limits to Growth: A report for the Club of Rome's project on the predicament of mankind. New York: Universe Books.

[8] Mezirow, J. (1991). Transformative Dimensions of Adult Learning. San Francisko: Jossey-Bass.

[9] Ortega y Gasset, J. (1930). La rebelión de las masas. Madrid: Revista de Occidente.

[10] Toffler, A. (1991). Powershift: Knowledge, Wealth, and Violence at the Edge of the 21st Century. New York: Bantam Books.

[11] Witkiewicz, S. I. (1919). Nowe formy w malarstwiei wynikające stąd nieporozumienia. Szkice estetyczne. Warszawa: Gebethner i Wolff. 